http://www.pakjas.com.pk

\title{
FARM RISK SOURCES AND THEIR MITIGATION: A CASE OF COTTON GROWERS IN PUNJAB
}

\author{
Muhammad Amjed Iqbal ${ }^{1, *}$, Qing Ping*2, Muhammad Usman Zafar ${ }^{3}$, Azhar Abbas ${ }^{1}$, \\ Muhammad Khalid Bashir ${ }^{1}$, Asghar Ali ${ }^{1}$ and Rakhshanda Kousar ${ }^{1}$ \\ ${ }^{1}$ Institute of Agricultural and Resource Economics, University of Agriculture Faisalabad, Pakistan; ${ }^{2,3}$ College of \\ Economics and Management, Huazhong Agricultural University, Wuhan, China \\ "Corresponding author's e-mail: amjed.iqbal@uaf.edu.pk, qingping@ mail.hzau.edu.cn
}

\begin{abstract}
For the last few years, cotton has been facing many risks from sowing till harvesting. These risks include natural, environmental, economic and marketing risks that cause severe impact on productivity and profitability of this crop. In Pakistan's context, such external and internal risk pose severe implications in terms of the provision of raw material to country's textile industry and foreign exchange earnings through textile exports. These in turn cast major threat to farmers' livelihood and industrial workers in the country. This study is conducted with the objective to provide an account of various risks faced by cotton growers, their awareness about these risks, their perceived impacts and relevant strategies for managing these risks at farm level in Punjab province of Pakistan. For this purpose, data from 480 cotton growers were collected from Punjab province using multistage random sampling technique. Results reveal that majority of the respondent's attribute yield reduction in cotton to various kinds of risks and are adapting to these risks as per their awareness about the risk and knowledge about potential mitigation and coping options. Frequent changes in agricultural policies are perceived to be the largest risk source in agriculture. On the other hand, necessity of constructing small dams and/or installation of turbines was deemed to be the top priority in managing various farm risks. Results also indicate some discrepancies among farmers in terms of their awareness about various risk sources and resultant coping and mitigation strategies. The study concludes with an emphasis on increasing farmers' awareness about potential risks and the need for participatory and community-based mitigation campaigns to ensure sustainable cotton production.
\end{abstract}

Keywords: Punjab, productivity, irrigation management, coping strategies, factor analysis

\section{INTRODUCTION}

Cotton crop is one the major sources of fiber in the world and to meet fiber requirements globally, this crop is cultivated in more than 100 countries (Cianchetta and Davis, 2015). While its uses are multifarious, it encounters numerous issues which constrain its production and availability in ample quantities. One of such factors is the frequently changing environmental condition. Others include socioeconomic, physio-geographic and political and agronomic-although some may influence cotton production directly while others indirectly - impeding cotton production (Luo et al., 2015). Pakistan being a developing country heavily relies on cotton economy as it is the fourth largest producer of cotton in the world, the third largest exporter of raw cotton, the third largest consumer of cotton, and the largest exporter of cotton yarn (GOP, 2016). Like other cotton producing nations, Pakistan has also witnessed severe setbacks in cotton production in recent years. For instance, during 2015-16, both cotton area and production declined by 1.5 and $27.8 \%$, respectively compared with previous year mainly due to a host of biological and ecological factors (GOP, 2016). Yield declines in recent years have been generally attributed to pink bollworm attack, lack of (or unavailability of irrigation water) at critical stages and price volatility (Abbas and Adil, 2018). Nevertheless, other risks have also emerged that can potentially cast serious impacts on cotton production particularly in Pakistan. Looking at the source of such risks and their impacts on cotton can provide valuable insights for their effective mitigation both at farm and policy levels. Studying such dynamics is quite common in case of other crops in many developed and developing countries but there is dearth of literature concerning cotton in Pakistan.

Prevalence of high and diverse risks is a general feature of farm production worldwide. Being highly unreliable sector of the economy, agriculture faces three types of risks namely production, marketing and financial risks (Iqbal et al., 2016). Cotton crop in Pakistan is widely open to many risks like intense rainfalls at sowing time, fast decreasing acreage, many diseases including leaf curl virus, attack of pests and use of faulty or conventional technology by the farmers (Kouser and Qaim, 2014). This situation is not particular with cotton but the whole agriculture in the country has remained highly risky compared with other businesses. Such risks 
originate from single or multifarious sources such as climate variation, uncertain prices, unpredictable government policies, international markets situation and other factors like geographical location, demographic variables and institutional structures leading to variations in farm incomes and significantly influencing goals, motivations and farm production decisions.

Although, different typologies are used to designate agricultural risks but they mainly involve production, marketing, financial, legal, human risks (Miller et al., 2004), or business risk involving production, marketing, institutional and personal risks (Hardaker et al., 2004), nevertheless, their mitigation is highly dependent on farmers' perceptions about the frequency and intensity (Meraner and Finger, 2017).

Risk perception plays a significant role in framing decisions to address anticipated or experienced risks. Risk perception is an individual's idea about the possibility of the incidence and impact of any risk event such as excessive rainfall, flood, drought or any other. This risk perception also includes individuals' consciousness about the happening, impact and possible coping options in its aftermath. For understanding a farmer's risk management strategies, one needs to fully comprehend his perceptions related to different dynamics of a risk event. On a broader scale, risk is not only related to individual farmer but it has concerns for the whole society. For example, a risk-averse farmer may decide not to opt modern technology due to potential risks attached with it but his decision can lead to implications for national output and overall welfare of the society if all individuals behave the same way. Therefore, welfare of the farmer's family and continuity of farming as business may depend on how farmers manage risks at farm level (Hardaker et al., 2004).

Risk management is a composite process that comprises of many steps. The first and foremost step is the identification of the risk and its nature. The next is to consider the occurrence of risk and to judge its consequences. The main focus generally remains on how much damage it can cause. Similarly, risk management in agriculture includes the selection and prioritization of risk mitigating methods depending on farmers' attitude towards risk. But alternatively, farm risk management is based on everything done to understand and deal with risk. In addition, risk assessment is the basic element of any risk management program. Okunmadewa (2003) has noted three basis types of risk management strategies namely prevention, mitigation and coping strategies. Nevertheless, the major responsibility lies with farm operator for selecting appropriate risk mitigation strategy given his/her financial background and other factors. In past few years, many studies have been conducted to look at farmers' risk perception and risk management strategies in Europe and USA (Flaten et al., 2005; Lien et al., 2006). These studies have served effectively as sources of data for policy practitioners and risk management professional. However, such type of studies is very rare in case of developing countries especially for Pakistan.

Farmers in Pakistan like other parts of the world face many risks in their farming activities. For example, only in the last decade they faced drought, severe floods, crop and animal diseases as well as frequent variations both in inputs and outputs prices along with others. Under such a scenario, evaluating sources of farm risks and farmers' management options becomes highly relevant for devising competitive measures through policy interventions. Therefore, this study was conducted to investigate various sources of risks faced by cotton growers in Punjab province along with studying risk management strategies (both mitigation and coping) used by them at farm level. The study also evaluated farmers' perceptions about the impacts of various risks in the study area.

\section{Methodology}

Study area and sampling method: Around 80 percent of cotton in Pakistan is generally produced in Punjab. Due to this fact, the study area comprised of randomly selected 6 cotton producing districts from Punjab. Another reason for selecting this province is high frequency and intensity of various catastrophes impeding cotton production in last few years. For actual data collection, a pretested questionnaire was used to gather socioeconomic, demographic, agronomic and riskrelated information from the subjects. A multi-stage sampling procedure was adopted used to select 480 farmers from randomly selected six districts viz. Khanewal, Vehari, Bahawalpur, Bahawalnagar, Muzaffar Garh and Rajan Pur based on their share in cotton production as shown in Figure 1. From each district, 80 respondents were randomly interviewed from randomly chosen union councils within each district. Survey was administered through face-to-face interviews due to high illiteracy rate among farming community within the study districts thus minimizing the use of web-based or postal survey.

Data and analytical procedure: Semi-structured questionnaire was used for data collection from cotton growers in study districts through personally interviewing respondents by 3 experienced enumerators. Closed type questions were asked from respondents where they were required to rank their response on a five-point Likert-type scale (Brown, 2011). Information sought included different risks sources, type of strategies they use to manage risk sources, their income sources, perceived impacts and various other household characteristics. Five options from 1 (strongly disagree) to 5 (strongly agree) were given to farmers for each risk source and risk management strategy. For the analysis of collected data, Statistical Package for Social Scientists (SPSS) software was used. Initially perception of farmers about risks sources and risk management strategies were analyzed using descriptive statistical analysis. The technique of common factor analysis (Ahsan, 2011; Meuwissan et al., 
2001; Bergfjord, 2009) was employed to reduce number of factors to principal components. The criterion for the selection of principal components was given by eigenvalue $\geq 1$. Sources of risks and strategies were divided into different factors according to rotated component matrix table or orthogonal varimax rotation table.

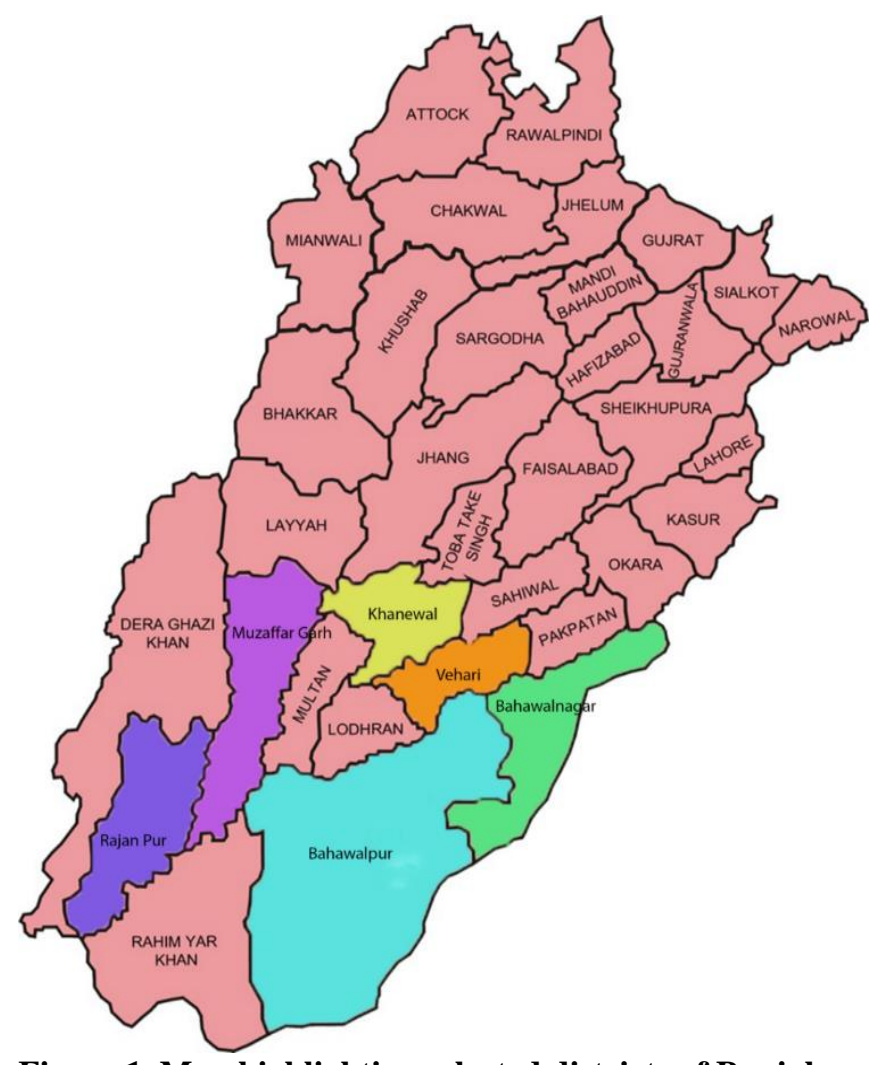

Figure 1. Map highlighting selected districts of Punjab.

Kaiser-Mayer-Olkin (KMO) value as a measure of sampling adequacy was 0.864 for risks sources and 0.762 for risk management strategies. As both values are more than 0.70, they show arrangement of correlation being compact and suitability of factor analysis. In the factor analysis technique, factor loading values of more than 0.30 reflect significant factors; factors with loading values of more than 0.40 are judged as more significant factors while those with more than 0.50 are considered as very significant (Akcaoz et al., 2009). In this study, a factor loading of higher than 0.40 is used to be illustrative of an important factor.

\section{RESULTS AND DISCUSSION}

Respondents' characteristics in terms of their age, years of education, farming experience, cotton growing experience, and total farm are considered to shape many farming and riskmitigation decisions at farm level. Farmers in the study area had on an average 7 years of schooling while average farming and cotton growing experience were 24 and 16 years, respectively. This shows that although the respondents have been involved in farming for a longer time period but due to crop rotation and experimenting with other crops led to relatively lesser cotton growing experience. In addition, about 41 percent of the respondent farmers (195 farmers of the total sample) did perform other activities along with farming as additional sources of income. Other salient characteristics of the respondents are given in Table 1.

Table 1. Socioeconomic characteristics of cotton farmers in the study area $(n=480)$.

\begin{tabular}{lc}
\hline Item & $\begin{array}{c}\text { Respondents } \\
\text { (No. /\%) }\end{array}$ \\
\hline Full time farmers (\%) & 59.40 \\
Part time farmers (\%) & 40.60 \\
Average Age (Years) & 46.84 \\
Family Size (average) & 7.79 \\
Average farm size (acre) & 17.19 \\
Cotton growing experience (years) & 15.91 \\
Farming experience (years) & 24.04 \\
No. of years of education & 7.33 \\
Farm gross monthly income (PKR.) & 55438.92 \\
\hline
\end{tabular}

Reasons for off-farm work: A relatively large percentage of farmers had income sources from off-farm work apart from farming. Such an attitude is also motivated by an intrinsic move to mitigate risk of complete bankruptcy in case farming suffers any blow being highly vulnerable to natural disasters and other risky events. The reasons for opting off-farm work revealed by the respondent farmers are given in Table 2 in the order of priority. For example, results in Table 2 show that low income from agriculture is considered as the top most reason to do off-farm activity revealed by about 25 percent farmers while 33 percent farmers told that burden of supporting large family is the second most reason to do any other activity.

Table 2. Reasons for participation in off-farm employment activities.

\begin{tabular}{ll}
\hline Reason & Respondents (\%) \\
\hline Low income from agriculture & 24.79 \\
Burden of supporting large family & 33.96 \\
Availability of off-farm opportunity & 23.11 \\
For increasing family income & 25.63 \\
Reduction of income risk from farming & 26.88 \\
Desire to work on something else & 26.46 \\
\hline
\end{tabular}

Farmer's perceptions of various risks sources: In order to elicit cotton farmers perceived or experienced risk sources in agriculture, they were required to record their response on a Likert scale about 19 potential risk sources. Table 3 shows the mean and standard deviation for each risk source which is calculated from the farmer's perception for each of these. 
Table 3. Mean scores and standard deviation of farmers' perceived risk sources.

\begin{tabular}{lccc}
\hline Risk Sources & Mean & Rank Std. Deviation \\
\hline Changes in agricultural policies & 3.96 & 1 & 0.55 \\
Price of farm equipment & 3.95 & 2 & 0.36 \\
Lack of farmers' cooperatives & 3.94 & 3 & 0.57 \\
Supply of private capital & 3.91 & 4 & 0.42 \\
Human health problem & 3.91 & 5 & 0.90 \\
Transportation issues & 3.90 & 6 & 0.96 \\
Supply of inputs & 3.84 & 7 & 0.96 \\
Difficulties in finding labour & 3.80 & 8 & 0.93 \\
Lack of information sources & 3.69 & 9 & 1.24 \\
Fluctuation in product prices & 3.65 & 10 & 1.72 \\
Fire & 3.61 & 11 & 0.80 \\
Prices of inputs & 3.55 & 12 & 0.93 \\
Severe weather conditions & 3.40 & 13 & 0.72 \\
Cotton diseases & 3.39 & 14 & 1.16 \\
Production uncertainty & 3.32 & 15 & 1.20 \\
Inadequate extension services & 3.24 & 16 & 1.01 \\
Lack of contract growing & 3.23 & 17 & 0.97 \\
Excessive rainfall & 3.07 & 18 & 1.09 \\
Insufficient family labour & 2.90 & 19 & 1.47 \\
\hline
\end{tabular}

$1=$ strongly disagree, $2=$ disagree, $3=$ neutral, $4=$ agree, $5=$ strongly agree.
Based on their mean values, reported risk sources faced by cotton growers are given in descending order. As the mean values indicate, most of the farmers' options are above 3 but below 4 which means they are more tilted towards 'agree' option placed at No. 4. In terms of farmers' response, changes in agricultural policies are perceived as the highest source of risk. The standard deviation of changes in agricultural policies is less than 1, which shows that cotton farmers are harmonized to accept it as the highest risk source. This finding is highly relevant with the farmer's perception as most of the policies related to agriculture have suffered from inconsistency and lack of implementation resulting in persistent food insecurity, rural poverty and low productivity (Hussain and Akram, 2008; Faruqee, 1999). Akcaoz and Ozkan (2005) have also found that changes in government and agricultural policies are one of the serious risk sources pertaining to agriculture.

Price of farm equipment is the second important risk source among cotton farmers with mean value of 3.95 implying that they generally agree to the statement being more close to $4^{\text {th }}$ option. Farm equipment are inputs needed for crop production. Fluctuating prices of farm equipment has been regarded as a risk source (Ahsan, 2011) and it was also reported as the second most important risk source by Akcaoz and Ozkan, (2005) in case of Turkey. The third main source

Table 4. Factor loading of risk sources.

\begin{tabular}{|c|c|c|c|c|c|c|}
\hline \multirow[t]{2}{*}{ Risk Sources } & \multirow[t]{2}{*}{ Mean } & \multicolumn{5}{|c|}{ Factor } \\
\hline & & 1 & 2 & 3 & 4 & 5 \\
\hline Changes in agricultural policies & 3.96 & -0.002 & 0.106 & 0.829 & -0.209 & -0.108 \\
\hline Price of farm equipment & 3.95 & -0.056 & -0.028 & 0.226 & 0.693 & 0.060 \\
\hline Lack of farmer cooperatives & 3.94 & 0.082 & -0.073 & 0.775 & 0.310 & 0.075 \\
\hline Supply of private capital & 3.91 & 0.002 & -0.020 & -0.169 & 0.774 & -0.075 \\
\hline Human health problem & 3.91 & 0.876 & 0.062 & 0.031 & -0.080 & -0.009 \\
\hline Transportation issues & 3.90 & 0.853 & 0.057 & -0.064 & 0.149 & 0.116 \\
\hline Supply of inputs & 3.84 & 0.850 & 0.106 & 0.048 & 0.088 & 0.012 \\
\hline Difficulties in finding labour & 3.80 & 0.934 & 0.076 & 0.003 & 0.069 & 0.085 \\
\hline Lack of information sources & 3.69 & 0.766 & -0.021 & 0.018 & -0.051 & -0.003 \\
\hline Fluctuation in product prices & 3.65 & -0.929 & 0.095 & -0.051 & 0.058 & 0.134 \\
\hline Fire & 3.61 & -0.001 & 0.367 & 0.107 & -0.211 & 0.474 \\
\hline Prices of inputs & 3.55 & -0.637 & 0.186 & 0.140 & 0.166 & 0.270 \\
\hline Severe weather condition & 3.40 & 0.053 & -0.020 & -0.099 & 0.083 & 0.874 \\
\hline Cotton disease & 3.39 & 0.113 & 0.702 & -0.121 & 0.085 & 0.049 \\
\hline Production uncertainty & 3.32 & 0.046 & 0.713 & -0.030 & 0.079 & -0.117 \\
\hline Inadequate extension services & 3.24 & 0.187 & 0.449 & 0.074 & -0.100 & 0.066 \\
\hline Lack of contract growing & 3.23 & -0.134 & 0.732 & 0.120 & -0.119 & 0.163 \\
\hline Excessive rainfall & 3.07 & 0.802 & 0.371 & -0.037 & -0.138 & 0.175 \\
\hline Insufficient family labour & 2.90 & 0.654 & 0.186 & 0.124 & -0.014 & 0.054 \\
\hline Eigenvalues & & 6.182 & 2.232 & 1.491 & 1.368 & 1.037 \\
\hline Percentage of the total variance & & 32.084 & 11.233 & 7.740 & 7.381 & 6.350 \\
\hline Cumulative percentage of total variance & & $32 / 084$ & 43.318 & 51.058 & 58.438 & 64.788 \\
\hline Bartlett's Test of Sphericity: & \multicolumn{6}{|c|}{ Approx. Chi-square $=4722.636(\mathrm{P}<0.001)$} \\
\hline
\end{tabular}


of risk was found to be the lack of farmers' cooperatives implying the need for such arrangement in the study area. The next important risk sources with same ranking are the supply of private capital and human health problems having equal ranking value of 3.91. As noted by Bergfjord (2009) and Ahsan (2011), supply of private capital served as an important risk source among Bangladeshi shrimp and Norwegian fish farmers, respectively Moreover, Family members' health situation as a risk source has been reported for the farmers in Norway (Lien et al., 2006). Uncertainty and inability in the supply of private capital and human health problems both can cause variation in crop (cotton) yield as it is necessary for the farmer to have sufficient capital to run farm operations successfully. Farming becomes highly constrained if household head's health and/or family members' health is compromised leading to productivity losses at the farm (Lien et al., 2006).

Transportation issues and adequate supply of inputs are considered the next important risk sources. These two issues cause considerable productivity losses as farm operations heavily depend on transport infrastructure for accessing both input and output markets. Untimely shortages of critical inputs like fertilizers, pesticides, approved seed and fuels have a strong bearing on smooth running of farm activities. Both these constraints work as double-edged sword - on one side burgeoning financial costs but faltering farm yields on the other side - intensifying farmers' problems if persist unabated (Bergfjord, 2009). Other sources of risk are ranked on the basis of mean values of farmers' response in Table 3. There are few risk sources for which farmers' response values are close to 3 meaning that the farmers neither agree nor disagree with the statement specifying various risk sources. In this case, excessive rainfall and insufficient family labor may be regarded as not so intensive risk sources.

Factor analysis for risk sources: Considering the abovementioned 19 risk sources, five factors were obtained through factor analysis using principle component extraction. These five factors have eigenvalues greater than 1 with a total variance of $64.88 \%$. Table 4 shows these five factors and their respective loadings (with variance accounted by the specific factor of more than 0.40). The value of Bartlett's test of sphericity is also highly significant. Out of the 19 factors (risk sources), 5 designated principal components (groups) based on their internal correlation are i) labour and market information, ii) production, iii) institutional, iv) financial and v) natural factors. The first factor has a higher loading on 'difficulties in finding labour', 'insufficient family labour', 'human health problem', 'excessive rainfall', 'supply of inputs', 'fluctuations in product prices', 'transportation issues', 'lack of information sources' and 'prices of inputs'. Factor 2 has greater association with 'production uncertainty', 'cotton diseases', 'lack of contract growing' and 'inadequate extension services'. As variables of factor 2 are related to production, so is named as 'production'. Factor 3 consists of 'changes in agricultural policies' and 'lack of farmers' cooperatives' and is designated as 'institutional'. Factor 4 is associated with the 'supply of private capital' and 'price of farm equipment' and is named as 'financial'. The 5th factor has higher loadings on 'severe weather conditions' and 'fire' and is called 'natural' (Table 4).

Farmers' perceived risk management strategies: Risk management strategies were arranged under 17 main variables like small dams, off-farm income sources and others as given in Table 5.

Table 5. Mean scores and standard deviation of farmers' perceived risk management strategies.

\begin{tabular}{lrrc}
\hline Strategies & Mean & Rank & $\begin{array}{c}\text { Std. } \\
\text { Deviation }\end{array}$ \\
\hline Small dams/turbine scheme & 4.39 & 1 & 0.93 \\
Off-farm income sources & 4.24 & 2 & 0.63 \\
Production diversity & 4.22 & 3 & 0.95 \\
Up to date market information & 4.04 & 4 & 0.39 \\
Provide trainings & 4.02 & 5 & 0.38 \\
Crop diversification & 3.97 & 6 & 0.40 \\
Adopt new technology & 3.96 & 7 & 0.35 \\
Assurance of bank loan & 3.92 & 8 & 0.55 \\
Contract farming & 3.88 & 9 & 0.57 \\
Prevent diseases & 3.80 & 10 & 0.64 \\
Personal insurance & 3.77 & 11 & 1.69 \\
Maintaining feed/inputs reserves & 3.76 & 12 & 0.61 \\
Timely supply of inputs & 3.53 & 13 & 0.97 \\
Establishing viable links with & 3.49 & 14 & 0.72 \\
extension \& other public bodies & & & \\
Stock of machinery & 3.41 & 15 & 0.73 \\
Taking safety measures & 3.36 & 16 & 0.65 \\
Growing multiple Varieties & 2.53 & 17 & 0.73 \\
\hline
\end{tabular}

$1=$ strongly disagree, $2=$ disagree, $3=$ neutral, $4=$ agree, $5=$ strongly agree.

Results in Table 5 indicate that reliance on small dams/ turbine schemes is the top ranked strategy having mean value of 4.39 implying that farmers response lies between agree and strongly agree option. Such a strategy is relevant as farmers do face frequent water shortages and heavy rainfall situations. This strategy is helpful in ensuring sufficient supply of water for irrigation while small dams would serve to protect farms from flood water. As noted by Qasim (2012), small dams/turbine schemes are highly useful in addressing sever risks of drought and flooding.

Off-farm income sources having mean response value of 4.24 are ranked second as risk management strategy. Farmers in general rely on off-farm income due to low purchasing power. To avoid financial deficiency at critical stages, off-farm income serves as a useful cushion and key risk management strategy (Akcaoz and Ozkan, 2005; Lien et al., 2006). Similarly, production diversity (using variety of production practices) and up to date market information are the next risk 
management strategies perceived by the farmers. Many farmers in developing countries use these strategies for ensuring smooth income streams from farming (Aditto et al., 2012; Qasim, 2012).

Providing training by NGOs and public bodies and crop diversification are ranked $5^{\text {th }}$ and $6^{\text {th }}$, respectively by the respondent cotton farmers as perceived risk management strategies. Providing trainings related to crop production, ICTs and equipment have been found to effectively equip farmers to combat potential risk sources (Ahsan, 2011). Adopting new technology, having assurance of bank loan, contract farming, preventing diseases are the succeeding perceived risk management strategies among cotton farmers in the study area. Ahsan and Roth (2010), in case of Denmark affirmed the adoption new technology as significant risk management strategy while preventing diseases before and after their onset are also common at many places (Ahsan, 2011). As majority of the farmers in the study rely on contract farming in the sense that they buy fertilizer, seed and other inputs from middleman or commission agents with the promise to sell their produce to them. So in this way farmers can manage their expenses and financial risks.

Other risk management strategies are personal insurance, maintaining feed/ input reserves, timely supply of inputs, having viable link with extension \& other public bodies, stock of machinery, taking safety measures and the use of multiple crop varieties (Table 5).

Factor analysis for risk management strategies: A factor analysis was conducted to these 17 risk management strategies. As presented in Table 6, five factors were extracted from these strategies having eigenvalue value above 1 which accorded 74.43 percent of total variance implying that this much variance is accounted for by the five principal factors. Also having a significant value of Bartlett's test of sphericity, factor analysis is justified. These factors are designated as 'capital management', 'credit', 'research and development', 'information management' and 'the diversification'.

Factor 1 has heavily loads on 'timely supply of inputs', 'small dams/turbine scheme', 'personal insurance', 'preventing diseases', 'maintaining feed/ input reserves', 'off-farm income', 'taking safety measures', 'production diversity' and 'stock of machinery'. This factor hence is named as capital management.

Factor 2 is designated as credit and includes the variables on 'assurance of bank loan' and 'contract farming'. Factor 3 has higher loadings on 'providing trainings' and 'adopting new technology' and is called as research and development. Factor 4 is related with 'up to date market information' and 'maintaining viable link with extension \& other public bodies' and so is designated as information management.

Table 6. Factor loading for risk management strategies.

\begin{tabular}{|c|c|c|c|c|c|c|}
\hline \multirow[t]{2}{*}{ Risk Management Strategies } & \multirow[t]{2}{*}{ Means } & \multicolumn{5}{|c|}{ Factors } \\
\hline & & 1 & 2 & 3 & 4 & 5 \\
\hline Small dams/turbine scheme & 4.39 & 0.901 & 0.012 & 0.008 & -0.014 & 0.260 \\
\hline Off-farm income sources & 4.24 & 0.712 & 0.117 & 0.062 & 0.037 & 0.175 \\
\hline Production diversity & 4.22 & 0.694 & 0.260 & -0.102 & -0.062 & 0.546 \\
\hline Up to date market information & 4.04 & 0.121 & 0.130 & -0.033 & 0.897 & 0.003 \\
\hline Provide trainings & 4.02 & 0.094 & -0.282 & 0.813 & 0.055 & -0.135 \\
\hline Crop diversification & 3.97 & -0.129 & -0.450 & 0.421 & 0.121 & 0.646 \\
\hline Adopt new technology & 3.96 & 0.003 & 0.200 & 0.873 & -0.018 & 0.067 \\
\hline Assurance of bank loan & 3.92 & 0.042 & 0.696 & 0.072 & 0.311 & -0.073 \\
\hline Contract farming & 3.88 & -0.104 & 0.611 & -0.109 & -0.157 & 0.182 \\
\hline Prevent diseases & 3.80 & 0.812 & 0.133 & 0.065 & 0.077 & 0.038 \\
\hline Personal insurance & 3.77 & 0.875 & 0.016 & -0.047 & -0.143 & 0.334 \\
\hline Maintaining feed/inputs reserves & 3.76 & 0.783 & -0.273 & 0.014 & -0.062 & -0.077 \\
\hline Timely supply of inputs & 3.53 & 0.936 & -0.064 & 0.026 & -0.093 & 0.126 \\
\hline $\begin{array}{l}\text { Establishing viable links with extension \& other } \\
\text { public bodies }\end{array}$ & 3.49 & -0.394 & -0.259 & 0.129 & 0.747 & -0.281 \\
\hline Stock of machinery & 3.41 & -0.525 & 0.516 & 0.031 & -0.275 & -0.083 \\
\hline Taking safety measures & 3.36 & -0.702 & 0.028 & -0.090 & -0.052 & -0.030 \\
\hline Growing multiple varieties & 2.53 & -0.310 & -0.211 & 0.201 & 0.282 & -0.778 \\
\hline Eigenvalues & & 6.150 & 2.381 & 1.616 & 1.425 & 1.081 \\
\hline Percentage of total variance & & 34.053 & 10.316 & 10.041 & 10.022 & 10.007 \\
\hline Cumulative percentage of total variance & & 34.053 & 44.369 & 54.410 & 64.432 & 74.439 \\
\hline Bartlett's Test of Sphericity & \multicolumn{6}{|c|}{ Approx. Chi-square $=6083.718(\mathrm{P}<0.001)$} \\
\hline
\end{tabular}


Lastly factor 5 is called as diversification as it has strong association with 'cultivating multiple varieties' and 'crop diversification'.

Conclusions: The study used primary data from cotton farmers to determine and evaluate risk sources and risk management strategies and perception of farmers about these risks. The study reveals major significant risks sources are change in agricultural policies, abrupt changes in prices of farm equipment and lack of farmers' cooperatives. In order to mitigate these risks, farmers do take various actions to ensure sustainability of their livelihoods. Although farmers take specific actions, they also perceive some other measures and actions as useful to increasing intensity of production, marketing, financial, natural and institutional risks.

Findings reveal that farmers give significant weightage to the necessary of constructing small dams and installation of turbines along with having additional off-farm income sources in order to feel themselves secure from ever increasing risky events particularly in the study area and in Pakistan in general. Study findings do highlight various policy implications for the sustainable development of agriculture - ranging from field operations to institutional support - in the form of easy access to credit, timely provision of critical inputs, active guidance from extension staff and other public bodies such as research, marketing and storage services.

Such interventions seem more plausible as farmers themselves have positive perceptions that they will prove to be more effective in addressing various issues (risk sources) being faced by them at the farm level.

An active and useful role of institutions is emphasized for creating an enabling environment for the sustainability of farming as a profitable venture. Such roles may include evidence-based research oriented to the solution of farm problems, marketing efficiency and information dissemination among farmers and organizations.

\section{REFERENCES}

Aditto, S., C. Gan and G.V. Nartea. 2012. Sources of risk and risk management strategies: The case of smallholder farmers in a developing economy. In: Risk ManagementCurrent Issues and Challenges. InTech, UK; pp.143-149.

Ahsan, D.A. 2011. Farmer's motivations, risk perceptions and risk management strategies in a developing economy: Bangladesh experience. J. Risk Res. 14:325-349.

Ahsan, D.A. and E. Roth. 2010. Farmer's perceived risks and risk management strategies in an emerging mussel aquaculture industry in Denmark. Mar. Resour. Eco. 25:309-323.

Akcaoz, H. and B. Ozkan. 2005. Determining risk sources and strategies among farmers of contrasting risk awareness: A case study for Cukurova region of Turkey. J. Arid Environ. 62:661-675.
Akcaoz, H., H. Kizilary and O. Ozcatalbas. 2009. Risk management strategies in dairy farming: A case study in Turkey. J. Anim. Vet. Adv. 8:949-958.

Abbas, A. and S.A. Adil. 2018. Evaluating international competitiveness of cotton production in Pakistan: A policy analysis matrix (PAM) approach. Policy Paper USPCAS-AFS, University of Agriculture Faisalabad, Pakistan.

Bergfjord, O.J. 2009. Risk perception and risk management in Norwegian aquaculture. J. Risk Res. 12:91-104.

Brown, J.D. 2011. Likert items and scales of measurement. Stat. 15:10-14.

Cianchetta, A.N. and R.M. Davis. 2015. Fusarium wilt of cotton: Management strategies. Crop Prot. 73:40-44.

Flaten, O., L. Gudbrand, K. Matthias, S.V. Paul and E. Martha. 2005. Comparing risk perceptions and risk management in organic and conventional dairy farming: Empirical results from Norway. Liv. Prod. Sci. 95:11-25.

Faruqee, R. 1995. Government's role in Pakistan agriculture: major reforms are needed, Vol. 1468. World Bank Publications. USA; pp.25-30.

GOP. 2014. Economic survey of Pakistan 2013-14. Finance and Economic Affairs Division, Ministry of Finance, Government of Pakistan, Islamabad, Pakistan.

GOP. 2015. Cotton production and exports. Punjab Agricultural Department, Government of Punjab. Available online at http://www.agripunjab.gov.pk/overview

Hair, J., J.F. Anderson, R.E. Tatham and W.C. Black. 2006. Multivariate data analysis. Upper Saddle River, NJ: Prentice-Hall, UK.

Hardaker, J.B., J.W.G. Richardson and D. Lien. 2004. Stochastic efficiency analysis with risk aversion bounds: a simplified approach. Aust. J. Agric. Resour. Eco. 48:253-270.

Hussain, Z. and W. Akram. 2008. Persistent food insecurity from policy failures in Pakistan. The Pak. Dev. Rev. 1:817-834.

Iqbal, M.A., Q. Ping, M. Abid, S.M.M. Kazmi and M. Rizwan. 2016. Assessing risk perceptions and attitude among cotton farmers: A case of Punjab province, Pakistan. Int. J. Disaster Risk Reduct. 16:68-74.

Kouser, S. and M. Qaim. 2014. Bt cotton, damage control and optimal levels of pesticide use in Pakistan. Environ. Dev. Eco. 19:704-723.

Lien, G., O. Flaten, A.M. Jervell, M. Ebbesvik, M. Koesling and P.S. Valle. 2006. Management and risk characteristics of part-time and full-time farmers in Norway. Rev. Agric. Eco. 1:111-131.

Luo, Q., M. Bange, D. Johnston and M. Braunack. 2015. Cotton crop water use and water use efficiency in a changing climate. Agric. Eco. Environ. 202:126-134. 
Meuwissan, M.P.M., R.B.M. Hurine and J.B. Hardaker. 2001. Risk and risk management: An empirical analysis of Dutch livestock farmers. Liv. Prod. Sci. 69:43-53.

Miller, A., C. Dobbins, J. Pritchett, M. Boehlje and C. Ehmke. 2004. Risk management for farmers. Department of Agricultural Economics Purdue University. Norvey. Liv. Prod. Sci. 95:11-25.

Meraner, M., and R. Finger. 2017. Risk perceptions, preferences and management strategies: evidence from a case study using German livestock farmers. J. Risk Res. 21:1-26.
Okunmadewa, F. 2003. Risk, vulnerability in agriculture: concept and context. Ph.D. Diss., Dept. Agric. Eco. Uni. Ibadan, Nigeria.

Qasim, M. 2012. Determinants of farm income and agricultural risk management strategies. The case of rainfed farm households in Pakistan's Punjab. Ph.D. Diss., Kassel Uni., Germany.

Sjoberg, L. 1998. World views, political attitudes and risk perception. Risk Health Saf. Environ. 9:137-152. 